\title{
Cumulative smoking exposure, duration of smoking cessation, and peripheral arterial disease in middle-aged and older Korean men
}

Young-Hoon Lee', Min-Ho Shin ${ }^{2}$, Sun-Seog Kweon ${ }^{2,3}$, Jin-Su Choi ${ }^{2}$, Jung-Ae Rhee², Hye-Ran Ahn², Woo-Jun Yun², So-Yeon Ryu ${ }^{4}$, Bok-Hee Kim ${ }^{5}$, Hae-Sung Nam ${ }^{6}$, Seul-Ki Jeong ${ }^{7}$, Kyeong-Soo Park ${ }^{8}$

\begin{abstract}
Background: We investigated the association of cumulative smoking exposure and duration of smoking cessation with peripheral arterial disease (PAD).

Methods: The study population consisted of 2517 community-dwelling Korean men aged 50 years and older. Information on smoking characteristics such as smoking status, pack-years of smoking, and years since quitting smoking was collected using a standardized questionnaire. PAD was defined as an ankle-brachial index (ABI) less than 0.90 in either leg.

Results: The odds ratio (OR, 95\% confidence interval) of PAD was 2.31 (1.20-4.42) for former smokers and 4.30 (2.13-8.66) for current smokers, after adjusting for other cardiovascular risk factors. There was a significant doseresponse relationship between pack-years of smoking and PAD. Compared with those who had never smoked, the multivariate-adjusted ORs of PAD for smokers of 0.1-20.0, 20.1-40.0, and >40.0 pack-years were 2.15 (1.06-4.38), 2.24 (1.08-4.65), and 2.93 (1.41-6.09), respectively. There was a significant decrease in PAD risk as the years since quitting smoking increased. The multivariate-adjusted ORs of PAD for 11-20 and $\geq 21$ years smoking cessation were 0.41 (0.19-0.86) and 0.49 (0.24-0.98), compared with current smokers.
\end{abstract}

Conclusions: Cumulative smoking exposure and duration of smoking cessation were significantly associated with PAD in middle aged and older Korean men.

\section{Background}

Peripheral arterial disease (PAD), one of the major manifestations of generalized atherosclerotic disease, results from a narrowing of arteries in the lower extremities, as a result of progressive atherosclerosis [1]. Although PAD is a marker of coronary and cerebral atherosclerotic vascular disease, PAD is a commonly overlooked condition in primary care settings, because most patients are asymptomatic. However, people with PAD, even if asymptomatic, have an increased risk of future cardiovascular events and related mortality [2-4]. The ankle-brachial index (ABI), the ratio of systolic blood pressure in the ankle to that in the arm, is a simple,

\footnotetext{
* Correspondence: mhshinx@paran.com

${ }^{2}$ Department of Preventive Medicine, Chonnam National University Medical School, Gwangju 501-746, Republic of Korea

Full list of author information is available at the end of the article
}

reproducible, and non-invasive test to diagnose PAD and has been used to diagnose and evaluate the severity of PAD in the lower extremities [5].

Cigarette smoking contributes to the constriction and damage of arteries and is a potent risk factor for PAD, by promoting endothelial dysfunction and by altering lipoprotein metabolism, coagulation, and platelet function [6]. A number of epidemiological studies have reported an association between PAD and both current and former smoking [7-14], though few studies have examined the cumulative effects of smoking, such as pack-years exposure, on PAD [15]. Moreover, because few studies have examined the association between smoking cessation and PAD [13], it remains undetermined whether the duration of smoking cessation is inversely associated with PAD in the general population.

\section{Biomed Central}

() 2011 Lee et al; licensee BioMed Central Ltd. This is an Open Access article distributed under the terms of the Creative Commons Attribution License (http://creativecommons.org/licenses/by/2.0), which permits unrestricted use, distribution, and reproduction in any medium, provided the original work is properly cited. 
The objective of our study was to investigate the association of cumulative cigarette smoking exposure with PAD prevalence among community-dwelling adults aged 50 years and older, and to determine whether the duration of smoking cessation was inversely associated with PAD.

\section{Methods}

\section{Subjects}

The study population consisted of community-dwelling men and women aged 50 years and older who participated in the 2007-2009 baseline surveys of the Dong-gu Study [16]. We used the national resident registration records to identify potential participants. In total, 26,323 eligible subjects aged 50 years and over who resided in one of five towns in the Dong-gu district of Gwangju Metropolitan City in South Korea were invited by telephone to participate. Total 6779 subjects were enrolled and the response rate for this study was $25.8 \%(21.8 \%$ for men and $29.1 \%$ for women). However, only men were included in the analysis because of the low prevalence of smoking in women (1.9\% current smokers and $1.8 \%$ former smokers). Of the 2644 men, 100 subjects were excluded from the study because of incomplete medical histories, lifestyle characteristics, and anthropometric and biochemical measurements. An additional 21 subjects were excluded because of missing information on the ABI measurements. Six individuals with an ABI greater than 1.50 were further excluded from the analysis because this indicates poorly compressible leg arteries and the inability to gauge arterial perfusion accurately $[17,18]$. In total, 2517 subjects were included in the analyses. This study was conducted in accordance with the Declaration of Helsinki guidelines and the study protocol was approved by the institutional review board of Chonnam National University Hospital. Participants provided written informed consent.

\section{Definition of smoking}

Participants were classified based on smoking habit information collected using a standardized questionnaire by well-trained research staff. Smoking was classified as never smokers (smoked <100 cigarettes in their lifetime and not currently smoking), former smokers (smoked $\geq 100$ cigarettes in their lifetime and currently a nonsmoker), and current smokers (smoked $\geq 100$ cigarettes in their lifetime and currently a smoker) [10]. Cumulative smoking exposure in former and current smokers was determined in terms of pack-years by multiplying the number of years smoked with the average number of packs per day [15]. Based on pack-years of smoking, subjects were classified as never smokers (0.0 packyears), light smokers (0.1-20.0 pack-years), moderate smokers (20.1-40.0 pack-years), and heavy smokers
(> 40 pack-years). Based on information on years since quitting smoking, former smokers were classified as $\leq 3$ years, 4-10 years, 11-20 years, and $\geq 21$ years and compared with current smokers.

\section{$A B I$ measurement and PAD definition}

$\mathrm{ABI}$, an indicator of PAD, was measured using an automated, non-invasive, waveform analysis device (VP1000, Colin Co, Komaki, Japan). The subjects were examined in the supine position after relaxing in the supine position on a bed for at least $5 \mathrm{~min}$. Cuffs were wrapped around both the arms and the ankles, and electrocardiogram electrodes were placed at the left sternal border. ABI was automatically calculated by dividing the posterior tibial systolic blood pressure by the brachial systolic pressure measured by the oscillometric method with cuffs adapted to the extremities. ABI was obtained for each leg separately, and the average was used as the mean ABI. PAD, or an abnormal ABI, was defined as an ABI of lower than 0.90 in either leg $[10,19]$. The absence of PAD was defined as an ABI $\geq 0.90$ and $\leq 1.50[17,20]$. An ABI less than 0.90 shows $95 \%$ sensitivity and $99 \%$ specificity for diagnosing PAD, as confirmed by angiography [21].

\section{Other variables of interest}

Information on the demographic characteristics, lifestyle, medical history, and medication use of each subject were assessed with a standardized questionnaire administered by trained staff. Alcohol consumption (g/day) was calculated from the average number of alcoholic beverages consumed. Physical exercise was categorized as none (0-1 time per week), irregular exercise (2-4 times per week), and regular exercise (5 or more times per week) [16]. Body mass index was calculated as weight in kilograms divided by height in meters squared. Blood pressure was measured after at least $5 \mathrm{~min}$ of rest in the sitting position using a mercury sphygmomanometer. The average of three consecutive readings of systolic and diastolic blood pressure taken at 1-min intervals was used in the analysis. After a 12-h overnight fast, venous blood samples were collected. Serum total cholesterol, high-density lipoprotein (HDL) cholesterol, triglycerides, uric acid, and fasting blood glucose levels were measured using enzymatic methods. Low-density lipoprotein (LDL) cholesterol was calculated by the Friedewald formula. All samples were analyzed using an automatic analyzer (Hitachi 7600, Hitachi Ltd., Tokyo, Japan).

\section{Statistical analysis}

General characteristics of the study population, based on the presence or absence of PAD, were expressed as mean \pm standard deviation or number (percentage), and 
were compared using independent $t$-tests for continuous variables and chi-squared tests for categorical variables. Analysis of covariance and multiple logistic regression were used to evaluate the association of smoking characteristics (e.g., smoking status, cumulative smoking exposure, and duration of smoking cessation) with mean $\mathrm{ABI}$ and PAD, respectively. Mean (standard error) or odds ratio (95\% confidence interval) were calculated in unadjusted, age-adjusted, and multivariate-adjusted models adjusting for age, body mass index, systolic blood pressure, fasting blood glucose, total cholesterol, HDL cholesterol, uric acid, alcohol consumption, physical exercise, and use of medications for hypertension, diabetes, and hyperlipidemia. Multivariate-adjusted models of cumulative smoking exposure were further adjusted for current smoking (yes/no), and multivariateadjusted models of duration of smoking cessation were additionally adjusted for pack-years of smoking. The trend in the association between smoking characteristics and PAD was determined after considering smoking categories as ordinal variables. All statistical analyses were performed using SPSS 15.0 and $P$ values $<0.05$ were deemed to indicate statistical significance.

\section{Results}

Among the 2517 men aged 50 years and older included in the analysis, 103 subjects had PAD (4.1\%) and 2414 subjects were classified as normal (95.9\%). General characteristics of the study population by the presence of PAD are presented in Table 1. Significant differences between those with and without PAD were observed in age, systolic blood pressure, uric acid, alcohol consumption, total years of smoking, packyears of smoking, and the use of antihypertensive and antidiabetic medications. The mean ABI was $0.868 \pm$ 0.117 in subjects with PAD and $1.147 \pm 0.082$ in subjects without PAD $(P<0.001)$.

Of all the subjects, 616 (24.5\%) had never smoked, 1298 (51.6\%) were former smokers, and 603 (24.0\%) were current smokers. Mean ABI and OR for PAD by smoking status are shown in Table 2. Compared to never smoking, former and current smokers had significantly smaller mean $\mathrm{ABI}$ in the unadjusted, age-adjusted, and multivariate-adjusted models $(P<0.001$ in all models). Moreover, current smokers had significantly smaller mean ABI than former smokers in all models. Former and current smokers had significantly higher risk for PAD than those who had never smoked. Compared with never smoking, the OR (95\% CI) for PAD was 2.31 (1.20-4.42) for former smokers and 4.30 (2.13-8.66) for current smokers in the multivariate-adjusted model. Furthermore, the risk of PAD in current smokers was significantly higher than in former smokers in the multivariate-adjusted model (OR, 1.89; 95\% CI, 1.19-3.01).
Table 1 General characteristics of the study population with and without PAD ( $n=2517)$

\begin{tabular}{|c|c|c|c|}
\hline & $\begin{array}{c}\text { Without } \\
\text { PAD } \\
(n=2414)\end{array}$ & $\begin{array}{l}\text { With PAD } \\
(n=103)\end{array}$ & $\begin{array}{c}P- \\
\text { value }^{\mathrm{a}}\end{array}$ \\
\hline Age, years & $65.9 \pm 7.9$ & $70.4 \pm 7.3$ & $<0.001$ \\
\hline Body mass index, $\mathrm{kg} / \mathrm{m}^{2}$ & $23.9 \pm 2.8$ & $23.4 \pm 3.0$ & 0.118 \\
\hline Systolic blood pressure, $\mathrm{mmHg}$ & $124.8 \pm 16.3$ & $129.6 \pm 19.5$ & 0.014 \\
\hline $\begin{array}{l}\text { Diastolic blood pressure, } \\
\mathrm{mmHg}\end{array}$ & $75.7 \pm 10.5$ & $74.8 \pm 10.0$ & 0.403 \\
\hline $\begin{array}{l}\text { Antihypertensive medications, } \\
\mathrm{n}(\%)\end{array}$ & $813(33.7)$ & $53(51.5)$ & $<0.001$ \\
\hline Fasting blood glucose, mg/dl & $113.3 \pm 27.2$ & $116.8 \pm 33.1$ & 0.205 \\
\hline Antidiabetic medications, n (\%) & $362(15.0)$ & $34(33.0)$ & $<0.001$ \\
\hline Total cholesterol, mg/dl & $187.7 \pm 37.7$ & $189.9 \pm 38.3$ & 0.567 \\
\hline LDL cholesterol, mg/dl & $109.7 \pm 35.7$ & $114.0 \pm 37.1$ & 0.231 \\
\hline HDL cholesterol, mg/dl & $49.3 \pm 12.0$ & $47.1 \pm 10.0$ & 0.073 \\
\hline Triglycerides, mg/dl ${ }^{b}$ & $143.7 \pm 116.5$ & $144.1 \pm 96.4$ & 0.977 \\
\hline $\begin{array}{l}\text { Lipid-lowering medications, } \\
n(\%)\end{array}$ & $150(6.2)$ & $6(5.8)$ & 0.873 \\
\hline Uric acid, mg/dl & $5.8 \pm 1.4$ & $6.4 \pm 1.9$ & 0.001 \\
\hline Alcohol consumption, gram/day & $14.8 \pm 23.7$ & $10.1 \pm 20.0$ & 0.023 \\
\hline Regular exercise, n (\%) & $492(20.5)$ & $16(15.7)$ & 0.239 \\
\hline Age at starting smoking & $22.4 \pm 5.6$ & $22.9 \pm 6.5$ & 0.427 \\
\hline Total years of smoking, years & $31.9 \pm 13.8$ & $36.8 \pm 14.9$ & 0.001 \\
\hline Number of cigarettes per day & $17.9 \pm 12.0$ & $19.1 \pm 12.7$ & 0.356 \\
\hline Pack-years of smoking & $21.5 \pm 22.2$ & $31.3 \pm 29.7$ & 0.001 \\
\hline Mean ankle-brachial index & $1.147 \pm 0.082$ & $\begin{array}{c}0.868 \pm \\
0.117\end{array}$ & $<0.001$ \\
\hline
\end{tabular}

Data are presented as means \pm standard deviation or number (percentage). PAD, peripheral arterial disease, was defined as an ankle-brachial index lesser than 0.90 in either leg; LDL, low-density lipoprotein; HDL, high-density lipoprotein.

${ }^{a} P$-value was obtained by Student's t-test or by chi-square test.

${ }^{\mathrm{b}} P$-value was obtained after log-transformation.

Table 3 shows the mean ABI and OR for PAD by cumulative smoking exposure. A significant decrease in mean ABI with pack-years of smoking was observed in all models ( $P$-trend $<0.001$ in all models). Additionally, compared with never smoking, light, moderate, and heavy smokers had significantly lower ABI in all models. Significant increases in PAD risk with pack-years of smoking were observed in all models $(P$-trend $<0.001$, $<0.001$, and $=0.008$, respectively). In the multivariateadjusted model, compared with those who had never smoked, the OR for PAD was 2.15 (1.06-4.38), 2.24 (1.08-4.65), and 2.93 (1.41-6.09) in light, moderate, and heavy smokers, respectively.

Table 4 shows the mean ABI and OR for PAD by years since quitting smoking. A significant doseresponse association was found between years since quitting smoking and mean $\mathrm{ABI}$ in all models ( $P$-trend $<0.001$ ). Former smokers with $11-20$ and $\geq 21$ years of smoking cessation had significantly greater mean ABI than individuals who had never smoked in all models. 
Table 2 Mean ankle-brachial index and odds ratio for peripheral arterial disease according to smoking status

\begin{tabular}{|c|c|c|c|}
\hline & \multicolumn{3}{|c|}{ Smoking status } \\
\hline & $\begin{array}{l}\text { Never smokers } \\
\quad(n=616)\end{array}$ & $\begin{array}{l}\text { Former smokers } \\
\quad(n=1298)\end{array}$ & $\begin{array}{l}\text { Current smokers } \\
\quad(\mathrm{n}=603)\end{array}$ \\
\hline \multicolumn{4}{|l|}{ Mean ankle-brachial index } \\
\hline Unadjusted & $1.156(0.004)$ & $1.134(0.003)^{* * *}$ & $1.118(0.004)^{* * *+\dagger}$ \\
\hline Age-adjusted & $1.157(0.004)$ & $1.134(0.003)^{* * *}$ & $1.116(0.004)^{* * *}+\dagger+$ \\
\hline Multivariate-adjusted ${ }^{\mathrm{a}}$ & $1.153(0.004)$ & $1.134(0.003)^{* * *}$ & $1.120(0.004)^{* * *+\dagger}$ \\
\hline \multicolumn{4}{|l|}{ Peripheral arterial disease ${ }^{b}$} \\
\hline Prevalence, n (\%) & $12(1.9)$ & $55(4.2)$ & $36(6.0)$ \\
\hline Unadjusted OR & 1.00 (reference) & $2.23(1.18-4.19)^{*}$ & $3.20(1.65-6.20)^{* *}$ \\
\hline Age-adjusted OR & 1.00 (reference) & $2.31(1.22-4.35)^{*}$ & $4.29(2.18-8.43)^{* * *}$ \\
\hline Multivariate-adjusted ${ }^{a} O R$ & 1.00 (reference) & $2.31(1.20-4.42)^{*}$ & $4.30(2.13-8.66)^{* * *}$ \\
\hline Unadjusted OR & - & 1.00 (reference) & $1.44(0.93-2.21)$ \\
\hline Age-adjusted OR & - & 1.00 (reference) & $1.87(1.20-2.92)+\dagger$ \\
\hline Multivariate-adjusted ${ }^{a} \mathrm{OR}$ & - & 1.00 (reference) & $1.89(1.19-3.01)+\dagger$ \\
\hline
\end{tabular}

Data are presented as mean (standard error) or odds ratio (95\% confidence interval).

${ }^{a}$ Adjusted for age, body mass index, systolic blood pressure, fasting blood glucose, total cholesterol, HDL cholesterol, uric acid, alcohol consumption, physical exercise, and use of medications for hypertension, diabetes, and hyperlipidemia.

${ }^{b}$ Defined as an ankle-brachial index lesser than 0.90 in either leg.

${ }^{*} P<0.05$, ${ }^{*} P<0.01$, ${ }^{* *} P<0.01$; compared with never smokers.

$\dagger P<0.05,+\dagger P<0.01,+\dagger+P<0.01$; compared with former smokers.

Risk for PAD decreased with increasing years since quitting smoking in all models $(P$-trend $=0.002,<0.001$, and $<0.001$, respectively). The risk of PAD in former smokers with 11-20 years and $\geq 21$ years of smoking cessation was significantly lower than in current smokers in all models, and the OR was $0.41(0.19-0.86)$ and 0.49 (0.24-0.98) in the multivariate-adjusted models, respectively.

\section{Discussion}

This cross-sectional study of community-dwelling Korean men demonstrated that cumulative smoking exposure was positively associated with $\mathrm{PAD}$, defined as an $\mathrm{ABI}<0.90$, and that duration of smoking cessation was inversely associated with PAD, independently of conventional cardiovascular risk factors. Although, as in previous studies, current smokers had a significantly higher risk for PAD than those

Table 3 Mean ankle-brachial index and odds ratio for peripheral arterial disease according to cumulative smoking exposure

\begin{tabular}{|c|c|c|c|c|c|}
\hline & \multirow{2}{*}{$\begin{array}{l}\text { Never smokers } \\
\quad(n=616)\end{array}$} & \multicolumn{3}{|c|}{ 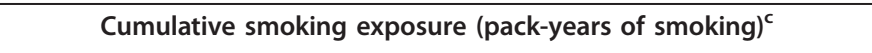 } & \multirow[t]{2}{*}{$P$-trend ${ }^{\mathrm{d}}$} \\
\hline & & $\begin{array}{c}\text { Light smokers } \\
{[0.1-20.0 \text { pack-years }]} \\
(\mathrm{n}=745)\end{array}$ & $\begin{array}{c}\text { Moderate smokers } \\
{[20.1-40.0 \text { pack-years }]} \\
(n=687)\end{array}$ & $\begin{array}{c}\text { Heavy smokers } \\
{[>40.0 \text { pack-years }]} \\
(n=438)\end{array}$ & \\
\hline \multicolumn{6}{|l|}{ Mean ankle-brachial index } \\
\hline Unadjusted & $1.156(0.004)$ & $1.138(0.004)^{* *}$ & $1.125(0.004)^{* * *}$ & $1.118(0.005)^{* * *}$ & $<0.001$ \\
\hline Age-adjusted & $1.156(0.004)$ & $1.138(0.004)^{* *}$ & $1.124(0.004)^{* * *}$ & $1.119(0.005)^{* * *}$ & $<0.001$ \\
\hline Multivariate-adjusted $^{a}$ & $1.150(0.004)$ & $1.137(0.004)^{*}$ & $1.128(0.004)^{* * *}$ & $1.123(0.005)^{* * *}$ & $<0.001$ \\
\hline \multicolumn{6}{|l|}{ Peripheral arterial disease ${ }^{b}$} \\
\hline Prevalence, $\mathrm{n}(\%)$ & $12(1.9)$ & $30(4.0)$ & $31(4.5)$ & $30(6.8)$ & \\
\hline Unadjusted OR & 1.00 (reference) & $2.11(1.07-4.16)^{*}$ & $2.38(1.21-4.67)^{*}$ & $3.70(1.87-7.31)^{* * *}$ & $<0.001$ \\
\hline Age-adjusted OR & 1.00 (reference) & $2.32(1.17-4.59)^{*}$ & $2.85(1.44-5.64)^{* *}$ & $3.69(1.86-7.31)^{* * *}$ & $<0.001$ \\
\hline Multivariate-adjusted ${ }^{\mathrm{a}} \mathrm{OR}$ & 1.00 (reference) & $2.15(1.06-4.38)^{*}$ & $2.24(1.08-4.65)^{*}$ & $2.93(1.41-6.09)^{* *}$ & 0.008 \\
\hline
\end{tabular}

Data are presented as mean (standard error) or odds ratio ( $95 \%$ confidence interval).

${ }^{a}$ Adjusted for age, body mass index, systolic blood pressure, fasting blood glucose, total cholesterol, HDL cholesterol, uric acid, alcohol consumption, physical exercise, use of medications for hypertension, diabetes, and hyperlipidemia, and current smoking (yes/no).

${ }^{b}$ Defined as an ankle-brachial index lesser than 0.90 in either leg.

'Thirty-one smokers were excluded due to lack of information about pack-years of smoking.

${ }^{\mathrm{d}} P$-trend estimated from analysis of covariance or logistic regression using the categories of cumulative smoking exposure as an ordinal variable.

${ }^{*} P<0.05,{ }^{* *} P<0.01$, ${ }^{* *} P<0.001$; compared with never smokers. 
Table 4 Mean ankle-brachial index and odds ratio for peripheral arterial disease according to duration of smoking cessation

\begin{tabular}{|c|c|c|c|c|c|c|c|}
\hline & \multirow{2}{*}{$\begin{array}{l}\text { Current smokers } \\
\quad(n=603)\end{array}$} & \multicolumn{4}{|c|}{ 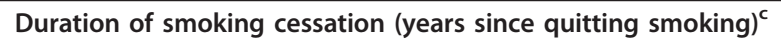 } & \multirow{2}{*}{$\begin{array}{l}\text { Never smokers } \\
\quad(n=616)\end{array}$} & \multirow[t]{2}{*}{$P$-trend } \\
\hline & & $\begin{array}{l}\leq 3 \text { years } \\
(n=185)\end{array}$ & $\begin{array}{c}4-10 \text { years } \\
(n=398)\end{array}$ & $\begin{array}{c}11-20 \text { years } \\
(\mathrm{n}=303)\end{array}$ & $\begin{array}{c}\geq 21 \text { years } \\
(\mathrm{n}=357)\end{array}$ & & \\
\hline \multicolumn{8}{|l|}{ Mean ankle-brachial index } \\
\hline Unadjusted & $1.118(0.004)$ & $1.127(0.007)$ & $1.130(0.005)$ & $1.140(0.006)^{* *}$ & $1.138(0.005)^{* *}$ & $1.156(0.004)^{* * *}$ & $<0.001$ \\
\hline Age-adjusted & $1.116(0.004)$ & $1.125(0.007)$ & $1.129(0.005)^{*}$ & $1.141(0.006)^{* * *}$ & $1.141(0.005)^{* * *}$ & $1.157(0.004)^{* * *}$ & $<0.001$ \\
\hline Multivariate-adjusted $^{a}$ & $1.123(0.004)$ & $1.132(0.008)$ & $1.134(0.005)$ & $1.139(0.006)^{*}$ & $1.138(0.005)^{*}$ & $1.147(0.005)^{* * *}$ & $<0.001$ \\
\hline \multicolumn{8}{|l|}{ Peripheral arterial disease ${ }^{b}$} \\
\hline Prevalence, $\mathrm{n}(\%)$ & $36(6.0)$ & $6(3.2)$ & $17(4.3)$ & $10(3.3)$ & $16(4.5)$ & $12(1.9)$ & \\
\hline Unadjusted OR & 1.00 (reference) & $0.53(0.22-1.27)$ & $0.70(0.39-1.27)$ & $0.54(0.26-1.10)$ & $0.74(0.40-1.35)$ & $0.31(0.16-0.61)^{* *}$ & 0.002 \\
\hline Age-adjusted OR & 1.00 (reference) & $0.49(0.20-1.19)$ & $0.59(0.32-1.08)$ & $0.41(0.20-0.84)^{*}$ & $0.47(0.25-0.88)^{*}$ & $0.23(0.12-0.45)^{* *}$ & $<0.001$ \\
\hline Multivariate-adjusted ${ }^{a} \mathrm{OR}$ & 1.00 (reference) & $0.47(0.19-1.17)$ & $0.57(0.30-1.06)$ & $0.41(0.19-0.86)^{*}$ & $0.49(0.24-0.98)^{*}$ & $0.25(0.11-0.55)^{* *}$ & $<0.001$ \\
\hline
\end{tabular}

Data are presented as mean (standard error) or odds ratio (95\% confidence interval).

${ }^{a}$ Adjusted for age, body mass index, systolic blood pressure, fasting blood glucose, total cholesterol, HDL cholesterol, uric acid, alcohol consumption, physical exercise, use of medications for hypertension, diabetes, and hyperlipidemia, and pack-year of smoking.

${ }^{b}$ Defined as an ankle-brachial index lesser than 0.90 in either leg.

${ }^{c}$ Fifty-five former smokers were excluded due to lack of information about years since quitting smoking.

${ }^{d} P$-trend estimated from analysis of covariance or logistic regression using the categories of years since quitting smoking as an ordinal variable.

${ }^{*} P<0.05,{ }^{*} P<0.01,{ }^{* *} P<0.001$; compared with current smokers.

who never or previously smoked, pack-years of smoking and years since quitting smoking were also identified as significant risk factors that should be taken into account to properly evaluate the effect of cigarette smoking on PAD.

The ABI is considered as a surrogate marker of generalized atherosclerosis because low ABI levels have been associated with elevated risk of future coronary heart disease [3,22], stroke [3,23,24], and a higher risk of all-cause and cardiovascular mortality $[3,25,26]$. A recent metaanalysis found that the predictive value of ABI for cardiovascular morbidity and mortality was similar to that of the traditional Framingham risk factors [27]. Because ABI is simple, non-invasive, reproducible, and cost-effective [28], $\mathrm{ABI}$ measurement is routinely performed to screen for asymptomatic PAD patients. ABI is a useful tool for the prediction of cardiovascular risk because, compared with carotid intima-media thickness and coronary artery calcium, it can be performed readily in community settings and in primary care physicians' offices [28].

Our results are consistent with previous findings that current smoking is associated with a 1.86 to 5.48 -fold increase in risk of PAD, compared with never having smoked [7-14]. Some studies have reported that current smoking is associated with a 1.60 to 2.80 -fold increase in the risk of PAD, compared with never or previously smoking $[29,30]$. Additionally, our findings are analogous to previous findings that former smoking is associated with a 1.02 to 1.94 -fold increased risk of PAD $[7,9-11,14]$; however, generally no significant difference between former and never smoking has been found.

Although various epidemiological studies have reported an association between smoking status and
PAD, the majority of studies have examined PAD risk by smoking status, finding that current smoking increased PAD risk or smoking cessation decreased PAD risk. However, the simple smoking status classification of never, former, and current smoking has been questioned on the assumption that lifetime heavy smokers who have recently stopped smoking are categorized as former smokers, whereas smokers who started smoking only a few months ago are categorized as current smokers. Thus, cumulative smoking exposure, such as pack-years, should be taken into account to properly evaluate the association between cigarette smoking and PAD. Because few studies have investigated the association between cumulative smoking exposure and PAD or between the duration of smoking cessation and PAD, the dose-response relationship between smoking habits (e.g., pack-years of smoking and years since quitting smoking) and PAD is uncertain. The Edinburgh Artery Study of 1592 adults reported that the adjusted relative risk of PAD, compared with never smoking, was 1.70 (95\% CI, 0.72-3.99) for moderate smokers ( $\leq 25$ packyears) and 2.72 (95\% CI, 1.13-6.53) for heavy smokers (> 25 pack-years) [15]. Recently, a cross-sectional study of 1215 Japanese men found that mean ABI correlated inversely and linearly with pack-years of smoking and the OR (95\% CI) of PAD, compared with never smoking, was 2.8 (0.8-10.2), 2.8 (0.8-10.0), and 4.2 (1.2-14.6) for $<26,26-45$, and $\geq 45$ pack-years, respectively, suggesting a linear trend [13]. In agreement with previous studies $[13,15]$, we observed a significant increasing trend between pack-years of smoking and PAD, confirming that the effect of cumulative smoking exposure on PAD 
was a dose-response relationship. Cui et al. [13] found that men who had quit smoking 20 or more years ago had higher mean ABI and lower prevalence of PAD than current smokers. In our study, the risk of PAD was significantly lower with smoking cessation of over 11 years than in current smokers, whereas $\leq 10$ years of smoking cessation was not significantly associated with PAD risk, suggesting that long-term smoking cessation is needed to diminish the effects of smoking on PAD.

\section{Study limitations and strengths}

There are several limitations to the present study. First, the cross-sectional nature limits conclusions about the direction or causality of associations observed in our study. Additional prospective studies with incident PAD are needed to confirm our findings. Second, the possible measurement errors in smoking characteristics due to the information being self-reported, without measuring biological markers, such as serum cotinine, might have attenuated the relationship between cigarette smoking and PAD. Third, unmeasured confounding variables could have affected the association of cigarette smoking and smoking cessation with PAD. Fourth, because information on environmental tobacco smoke exposure was not collected, the effect of passive smoking on PAD cannot be accessed.

Nevertheless, this study has several strengths. First, the main strength is that few studies have investigated the association between smoking characteristics (including pack-years of smoking and years since quitting smoking) and PAD risk. Our more detailed analysis, compared with previous studies, allowed us to find a significant association between smoking habits and PAD. Second, $A B I$ was measured on both the left and right sides, and the smallest ABI was used in defining PAD. Third, a large number of community-dwelling older men participated in this study. Because subclinical atherosclerosis progresses with age, the present study population (aged 50 years and older) may help detect an association between smoking habits and PAD.

\section{Conclusions}

In summary, a significant dose-response association between cumulative smoking exposure and PAD prevalence was found in a community-dwelling sample of Korean men. Additionally, there was a significant inverse association between duration of smoking cessation and presence of PAD. From a public health perspective, considering the high prevalence of current smoking in Korean men, more aggressive tobacco control efforts could reduce the number of people who develop PAD.

\section{Acknowledgements}

This study was financially supported by Chonnam National University, 2007

\section{Author details}

${ }^{1}$ Regional Cardiocerebrovascular Center, Chonnam National University Hospital, Gwangju 501-757, Republic of Korea. ${ }^{2}$ Department of Preventive Medicine, Chonnam National University Medical School, Gwangju 501-746, Republic of Korea. ${ }^{3}$ Jeonnam Regional Cancer Center, Chonnam National University Hwasun Hospital, Jeollanamdo 519-809, Republic of Korea. ${ }^{4}$ Department of Preventive Medicine, Chosun University College of Medicine, Gwangju 501-759, Republic of Korea. ${ }^{5}$ Department of Food and Nutrition, College of Natural Sciences, Chosun University, Gwangju 501-759, Republic of Korea. ${ }^{6}$ Department of Preventive Medicine, Chungnam National University College of Medicine, Daejeon 301-747, Republic of Korea. ${ }^{7}$ Department of Neurology, Chonbuk National University Medical School, Jeonju 561-180, Republic of Korea. ${ }^{8}$ Department of Preventive Medicine, Seonam University College of Medicine, Jeollabukdo 590-711, Republic of Korea.

\section{Authors' contributions}

YHL carried out physical examinations, analyzed the data, and drafted the manuscript. MHS and SSK coordinated the data collection and also performed physical examinations. HRA, WJY, SYR, BHK, HSN, SKI, and KSP conducted physical measurements and collected data. JSC and JAR participated in the design of the study, the data collection, and reviewed the manuscript. All authors read and approved the final manuscript to be published.

\section{Competing interests}

The authors declare that they have no competing interests.

Received: 1 November 2010 Accepted: 11 February 2011 Published: 11 February 2011

\section{References}

1. Newman AB, Siscovick DS, Manolio TA, Polak J, Fried LP, Borhani NO, Wolfson SK: Ankle-arm index as a marker of atherosclerosis in the Cardiovascular Health Study Cardiovascular Heart Study (CHS) Collaborative Research Group. Circulation 1993, 88:837-845.

2. Priollet $P$ : Quality of life and peripheral arterial disease: perspectives for the future. Drugs 1998, 56:49-58.

3. Newman AB, Shemanski L, Manolio TA, Cushman M, Mittelmark M, Polak JF, Powe NR, Siscovick D: Ankle-arm index as a predictor of cardiovascular disease and mortality in the Cardiovascular Health Study. The Cardiovascular Health Study Group. Arterioscler Thromb Vasc Biol 1999, 19:538-545.

4. Murabito JM, Evans JC, Larson MG, Nieto K, Levy D, Wilson PW, Framingham Study: The ankle-brachial index in the elderly and risk of stroke, coronary disease, and death: the Framingham Study. Arch Intern Med 2003, 163:1939-1942.

5. Feigelson HS, Criqui MH, Fronek A, Langer RD, Molgaard CA: Screening for peripheral arterial disease: the sensitivity, specificity, and predictive value of noninvasive tests in a defined population. Am J Epidemiol 1994, 140:526-534.

6. Lu JT, Creager MA: The relationship of cigarette smoking to peripheral arterial disease. Rev Cardiovasc Med 2004, 5:189-193.

7. Meijer WT, Grobbee DE, Hunink MG, Hofman A, Hoes AW: Determinants of peripheral arterial disease in the elderly: the Rotterdam study. Arch Intern Med 2000, 160:2934-2938.

8. Murabito JM, Evans JC, Nieto K, Larson MG, Levy D, Wilson PW: Prevalence and clinical correlates of peripheral arterial disease in the Framingham Offspring Study. Am Heart J 2002, 143:961-965.

9. Navas-Acien A, Selvin E, Sharrett AR, Calderon-Aranda E, Silbergeld E, Guallar E: Lead, cadmium, smoking, and increased risk of peripheral arterial disease. Circulation 2004, 109:3196-3201.

10. Selvin $E$, Erlinger TP: Prevalence of and risk factors for peripheral arterial disease in the United States: results from the National Health and Nutrition Examination Survey 1999-2000. Circulation 2004, 110:738-743.

11. Wattanakit K, Folsom AR, Selvin E, Weatherley BD, Pankow JS, Brancati FL, Hirsch AT: Risk factors for peripheral arterial disease incidence in persons with diabetes: the Atherosclerosis Risk in Communities (ARIC) Study. Atherosclerosis 2005, 180:389-397.

12. Eason SL, Petersen NJ, Suarez-Almazor M, Davis B, Collins TC: Diabetes mellitus, smoking, and the risk for asymptomatic peripheral arterial disease: whom should we screen? J Am Board Fam Pract 2005, 18:355-361. 
13. Cui R, Iso H, Yamagishi K, Tanigawa T, Imano H, Ohira T, Kitamura A, Sato S, Shimamoto T: Relationship of smoking and smoking cessation with ankle-to-arm blood pressure index in elderly Japanese men. Eur J Cardiovasc Prev Rehabil 2006, 13:243-248.

14. Ostchega Y, Paulose-Ram R, Dillon CF, Gu Q, Hughes JP: Prevalence of peripheral arterial disease and risk factors in persons aged 60 and older: data from the National Health and Nutrition Examination Survey 19992004. J Am Geriatr Soc 2007, 55:583-589.

15. Price JF, Mowbray PI, Lee AJ, Rumley A, Lowe GD, Fowkes FG: Relationship between smoking and cardiovascular risk factors in the development of peripheral arterial disease and coronary artery disease: Edinburgh Artery Study. Eur Heart J 1999, 20:344-353.

16. Lee YH, Shin MH, Kweon SS, Choi SW, Kim HY, Ryu SY, Kim BH, Rhee JA Choi JS: Alcohol consumption and carotid artery structure in Korean adults aged 50 years and older. BMC Public Health 2009, 9:358.

17. McDermott MM, Criqui MH, Liu K, Guralnik JM, Greenland P, Martin GJ, Pearce $W$ : The lower ankle brachial index calculated by averaging the dorsalis pedis and posterior tibial arterial pressures is most closely associated with leg functioning in peripheral arterial disease. J Vasc Surg 2000, 32:1164-1171.

18. Lange SF, Trampisch HJ, Pittrow D, Darius H, Mahn M, Allenberg JR, Tepohl G, Haberl RL, Diehm C, getABI Study Group: Profound influence of different methods for determination of the ankle brachial index on the prevalence estimate of peripheral arterial disease. BMC Public Health 2007, 7:147.

19. Stoffers HE, Kester AD, Kaiser V, Rinkens PE, Kitslaar PJ, Knottnerus JA: The diagnostic value of the measurement of the ankle-brachial systolic pressure index in primary health care. J Clin Epidemiol 1996, 49:1401-1405.

20. McDermott MM, Guralnik JM, Greenland P, Pearce WH, Criqui MH, Liu K, Taylor L, Chan C, Sharma L, Schneider JR, Ridker PM, Green D, Quann M: Statin use and leg functioning in patients with and without lowerextremity peripheral arterial disease. Circulation 2003, 107:757-761.

21. Bernstein EF, Fronek A: Current status of noninvasive tests in the diagnosis of peripheral arterial disease. Surg Clin North Am 1982, 62:473-487.

22. Abbott RD, Petrovitch H, Rodriguez BL, Yano K, Schatz IJ, Popper JS, Masaki KH, Ross GW, Curb JD: Ankle/brachial blood pressure in men $>70$ years of age and the risk of coronary heart disease. Am J Cardiol 2000, 86:280-284.

23. Abbott RD, Rodriguez BL, Petrovitch H, Yano K, Schatz IJ, Popper JS, Masaki KH, Ross GW, Curb JD: Ankle-brachial blood pressure in elderly men and the risk of stroke: the Honolulu Heart Program. J Clin Epidemiol 2001, 54:973-978.

24. Tsai AW, Folsom AR, Rosamond WD, Jones DW: Ankle-brachial index and 7-year ischemic stroke incidence: the ARIC study. Stroke 2001, 32:1721-1724.

25. Criqui MH, Langer RD, Fronek A, Feigelson HS, Klauber MR, McCann TJ, Browner D: Mortality over a period of 10 years in patients with peripheral arterial disease. N Engl J Med 1992, 326:381-386.

26. Vogt MT, Cauley JA, Newman AB, Kuller LH, Hulley SB: Decreased ankle/ arm blood pressure index and mortality in elderly women. JAMA 1993, 270:465-469.

27. Ankle Brachial Index Collaboration, Fowkes FG, Murray GD, Butcher I, Heald CL, Lee RJ, Chambless LE, Folsom AR, Hirsch AT, Dramaix M, deBacker G, Wautrecht JC, Kornitzer M, Newman AB, Cushman M, SuttonTyrrell K, Fowkes FG, Lee AJ, Price JF, d'Agostino RB, Murabito JM, Norman PE, Jamrozik K, Curb JD, Masaki KH, Rodríguez BL, Dekker JM, Bouter LM, Heine RJ, Nijpels G, Stehouwer CD, Ferrucci L, McDermott MM, Stoffers HE, Hooi JD, Knottnerus JA, Ogren M, Hedblad B, Witteman JC, Breteler MM, Hunink MG, Hofman A, Criqui MH, Langer RD, Fronek A, Hiatt WR, Hamman R, Resnick HE, Guralnik J, McDermott MM: Ankle brachial index combined with Framingham Risk Score to predict cardiovascular events and mortality: a meta-analysis. JAMA 2008, 300:197-208.

28. Khan TH, Farooqui FA, Niazi K: Critical review of the ankle brachial index. Curr Cardiol Rev 2008, 4:101-106.

29. Sritara P, Sritara C, Woodward M, Wangsuphachart S, Barzi F, Hengprasith B, Yipintsoi T: Prevalence and risk factors of peripheral arterial disease in a selected Thai population. Angiology 2007, 58:572-578.
30. Tapp RJ, Balkau B, Shaw JE, Valensi P, Cailleau M, Eschwege E, DESIR Study Group: Association of glucose metabolism, smoking and cardiovascular risk factors with incident peripheral arterial disease: the DESIR study. Atherosclerosis 2007, 190:84-89.

\section{Pre-publication history}

The pre-publication history for this paper can be accessed here: http://www.biomedcentral.com/1471-2458/11/94/prepub

\section{doi:10.1186/1471-2458-11-94}

Cite this article as: Lee et al:: Cumulative smoking exposure, duration of smoking cessation, and peripheral arterial disease in middle-aged and older Korean men. BMC Public Health 2011 11:94.

\section{Submit your next manuscript to BioMed Central and take full advantage of:}

- Convenient online submission

- Thorough peer review

- No space constraints or color figure charges

- Immediate publication on acceptance

- Inclusion in PubMed, CAS, Scopus and Google Scholar

- Research which is freely available for redistribution

Submit your manuscript at www.biomedcentral.com/submit
Biomed Central 